
$\$$ Research Square
Preprints are preliminary reports that have not undergone peer review.
They should not be considered conclusive, used to inform clinical practice,
or referenced by the media as validated information.

\title{
The Effectiveness of Binaural Beat Audio on Anxiety State In Patients Undergoing Fiberoptic Bronchoscopy: A Prospective Randomised Controlled Trial
}

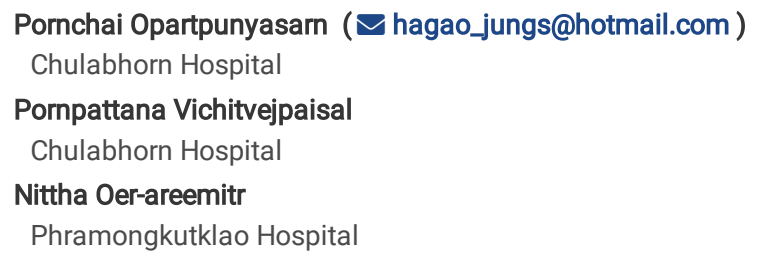

\section{Research article}

Keywords: Binaural beat, Music, Anxiety, Bronchoscopy

Posted Date: October 7th, 2020

DOI: https://doi.org/10.21203/rs.3.rs-68791/v1

License: @ (i) This work is licensed under a Creative Commons Attribution 4.0 International License. Read Full License 


\section{Abstract}

Background:

Fiberoptic bronchoscopy is an invasive procedure known to contribute anxiety in patients. Binaural beat, an audio technology with different frequency between ears to entrain the brainwaves, has been used to reduce anxiety in some operations. This study aimed to determine the anxiolytic effects of binaural beat in patients undergoing fiberoptic bronchoscopy.

\section{Methods:}

All eligible subjects were randomly assigned to receive binaural beat music, plain music, or no music. They were asked to wear earphones approximately 15 minutes before, during, and after the bronchoscopy. The level of anxiety was measured with State-Trait Anxiety Inventory (STAl) questionnaires. Blood pressure, heart rate, and sedative drug use were also recorded.

\section{Results:}

One hundred and twelve subjects were included and randomised into 3 groups, including binaural beat music ( $n=38)$, plain music ( $n=38)$, and no music $(n=36)$. Baseline characteristics were non-significantly different between the groups. The mean change of post-bronchoscopy STAI state scores in binaural beat music, plain music, and no music groups was $-7.26(p<0.001),-3.92(p=0.005)$, and $-1.12(p=0.454)$, respectively. The mean systolic blood pressure and diastolic blood pressure were significantly decreased from baseline for $-9.89(p=0.002)$ and $-5.76(p=0.005)$, respectively in binaural group. The mean heart rate were increased from baseline for $3.32(p=0.035), 5.21(p=0.038)$, and $3.64(p=0.149)$ in binaural beat music, plain music, and no music groups, respectively.

\section{Conclusions:}

The binaural beat music was proven to reduce anxiety among patients undergoing fiberoptic bronchoscopy.

\section{Trial registration:}

TCTR, TCTR20200915002. Registered 14 September 2020 - Retrospectively registered.

\section{Background}

Fiberoptic bronchoscopy is a diagnostic and therapeutic respiratory procedure for visualizing inside the airways to obtain samples of lung tissue or bronchoalveolar lavage and remove foreign bodies or mucus plug. Bronchoscopists have to insert the bronchoscope tube into the airways, usually through a nose or mouth, or occasionally through a tracheostomy. Most patients are afraid of pain and feel stressed with aspiration, breathing difficulty, and complications. Whereas, conscious sedation with opioid and/or benzodiazepine has been used to relieve patients' discomfort and anxiety during the procedure $[1,2,3]$. However, the high dose of these drugs can lead to unfavorable side effects, such as cardiovascular and respiratory suppression.

Music therapy is suggested as a safe and affordable non-pharmacologic means for the relief of stress and anxiety in patients with different interventional procedures $[4,5]$. Previous studies demonstrated beneficial outcomes of music therapy, including a shorter operative time, fewer sedative drug use, and lower level of pain $[5,6,7]$. Wilson's meta-analysis revealed that listening to music reduced blood pressure and heart rate among patients undergoing bronchoscopy [8]. Musical sound could affect the emotional and physiological regions of the brain relating to the perioperative anxiety (e.g., blood pressure and heart rate). In particular, the sound of music controls the releasing of cortisol, which is an essential hormone for stress responses [9].

Binaural beat music was described as a special type of audio by Gerald Oster over 40 years ago [10]. It has recently been considered as a therapeutic tool for neuropsychologists and clinicians, with its potential to decrease perioperative anxiety in previous reports [11, 12]. This could be generated when two audio waves of different frequency present to each ear separately. Nonetheless, the frequency of these waves must be lower than $1,000 \mathrm{hertz}(\mathrm{Hz})$. For binaural beat audio, the recommended frequency of different pitch has to be effectively lower than $30 \mathrm{~Hz}$. For instance, with the sound pitch of $450 \mathrm{~Hz}$ and $460 \mathrm{~Hz}$ delivered to the left and the right ears by the headphone, the binaural beat frequency should be $10 \mathrm{~Hz}$ in the alpha range of brainwave associated with relaxation.

Thus, we aimed to determine the anxiolytic effect of binaural beat audio compared with plain music without binaural beat and no musical intervention in patients undergoing fiberoptic bronchoscopy.

\section{Methods Study design}

This was a prospective, randomised, double-blind, controlled trial. The study protocol was approved by Institutional Review Board, Royal Thai Army Medical Department, Phramongkutklao College of Medicine. Written informed consent was obtained from all subjects after the receipt of written information, with the opportunity to ask questions from the investigators.

\section{Subjects}


Patients aged $\geq 18$ years were recruited and scheduled for elective fiberoptic bronchoscopy under intravenous sedation at Pulmonary and Critical Care Division, Phramongkutklao Hospital, Thailand, from May 2018 to July 2019. Those with hearing impairment, ear infection, history of epilepsy, cognitive dysfunction, cardiac arrhythmia, and blood pressure $<90 / 60 \mathrm{mmHg}$ or $>160 / 100 \mathrm{mmHg}$ were excluded.

\section{Randomisation}

Eligible subjects were randomised into three groups by using block randomization (block of six), including binaural group (music with binaural beat), plain music group (identical soundtrack without binaural beat), and control group (earphones with soundless music). Bronchoscopists and investigators who opened the mp3 audio file were blinded. Subjects were also blinded to the intervention.

\section{Interventions}

Being synthesized with the Self Hypnosis and Relaxation Machine (S.H.A.R.M., CyberTeam, Ltd., Informer Technologies Inc., Madrid, Spain) version 2.4 and the utilization of carrier tones at 109 and $209 \mathrm{~Hz}$, the binaural beat audio had a frequency of $20 \mathrm{~Hz}$ during the first 5 minutes, before getting gradually declined to the $10 \mathrm{~Hz}$ therapeutic frequency within 5 minutes later and continually maintained up to 50 minutes. There were relaxing melodies, tones, and rhythms in the 60-minute binaural beat music, with the added nature sounds like waterfall, bird chirping, ocean, river, and forest, as MP3 audio format of high quality for the binaural beat music group. While, the plain music with no binaural beat was assigned to the plain music group. Nonetheless, the binaural beat was hard for detection in the experimental group.

All bronchoscopic procedures were performed in the supine posture. Before the procedure, subjects were assigned to receive 1 audio file from randomisation. MP3 player and earphones (Remax Sport Wired Headset: RM-S15) were given to all groups for playing music, including silent music in the control group. Earphones were placed in both ears of the subjects about 15 minutes before, during, and after the bronchoscopy. An appropriate level of volume was chosen for subjects to hear the bronchoscopist's communication. The bronchoscopists were not aware of the subjects' intervention group.

\section{Assessment Of Anxiety}

The effect of binaural beat audio was examined on anxiety status by State-Trait Anxiety Inventory (STAl) questionnaires. The anxiety was measured by questionnaires with the state subscale (STAI-S) and the trait subscale (STAI-T). The STAI-S comprised 20 questions to determine how the subjects "feel right now". Whereas, the STAI-T included 20 questions to assess how the subjects "generally feel". The scores for both subscales each ranged from 20 to 80 with higher scores in correspondence to higher levels of anxiety $[13,14,15]$. The subjects were asked to complete both STAI-S and STAI-T questionnaires on a day of bronchoscopy before wearing the earphones. The STAI-S was done for the second time after the bronchoscopic procedure.

Blood pressure and heart rate were objective measurements of anxiety. Systolic blood pressure (SBP), diastolic blood pressure (DBP), and heart rate (HR) were measured before using earphones and 15 minutes after bronchoscopy. Also, the amount of sedative and analgesic use was recorded.

\section{Outcomes}

The primary outcome was the changes in anxiety level measured by STAl-S before and after the bronchoscopy. The secondary outcomes were the SBP, DBP and HR changes after the bronchoscopy and total amount of sedative and analgesic drugs used in the procedure. Duration of the procedure and intrabronchoscopic adverse events were also recorded.

\section{Statistical analysis}

Following the data from previous studies [12], a sample size of 27 in each group was required to provide $90 \%$ power and $5 \%$ type I error. Statistical analysis was performed using SPSS version 23.0, with One-way ANOVA test for continuous variables and Chi-square test for categorical variables. Paired t-test and Bonferroni test were applied for the differences within and between the groups, respectively. P-value $\leq 0.05$ was considered statistically significant.

\section{Results}

From May 2018 to July 2019, 116 subjects were scheduled for the bronchoscopic procedure and included in the study. Of these, 4 subjects were excluded due to hearing impairment $(n=2)$ and cognitive dysfunction $(n=2)$. The remaining 112 subjects were randomised into the binaural beat music $(n=38)$, the plain music $(n=38)$, and the control $(n=36)$ groups. Seven subjects ( 2 in the plain music group, 2 in the binaural group, and 3 in the control group) did not complete the STAI-S questionnaire (Fig. 1). There were no significant differences of demographic data and covariant factors between the groups (Table 1). 
Table 1

Demographic data

\begin{tabular}{|c|c|c|c|c|}
\hline Variable & $\begin{array}{l}\text { Plain music } \\
(n=38)\end{array}$ & $\begin{array}{l}\text { Binaural } \\
(n=38)\end{array}$ & $\begin{array}{l}\text { Control } \\
(n=36)\end{array}$ & P-value \\
\hline Age & $58.05 \pm 11.99$ & $57.76 \pm 13.34$ & $56.72 \pm 14.13$ & 0.902 \\
\hline \multicolumn{5}{|l|}{ Sex } \\
\hline Male & $27(71.1 \%)$ & $21(55.3 \%)$ & $21(58.3 \%)$ & 0.326 \\
\hline \multicolumn{5}{|l|}{ Underlying disease } \\
\hline DM & $3(7.9 \%)$ & $6(15.8 \%)$ & $10(27.8 \%)$ & 0.073 \\
\hline HT & $12(31.6 \%)$ & $13(34.2 \%)$ & $12(33.3 \%)$ & 0.970 \\
\hline Cardiovascular disease & $1(2.6 \%)$ & $1(2.6 \%)$ & $3(8.3 \%)$ & 0.394 \\
\hline Respiratory disease & $6(15.8 \%)$ & $8(21.1 \%)$ & $1(2.8 \%)$ & 0.061 \\
\hline Malignancy & $10(26.3 \%)$ & $10(26.3 \%)$ & $9(25 \%)$ & 0.989 \\
\hline Other & $12(31.6 \%)$ & $12(31.6 \%)$ & $7(19.4 \%)$ & 0.407 \\
\hline \multicolumn{5}{|l|}{ Drug use } \\
\hline Beta blocker & $1(2.6 \%)$ & $2(5.3 \%)$ & $2(5.6 \%)$ & 0.796 \\
\hline Sedative or anxiolytic & $6(15.8 \%)$ & $6(15.8 \%)$ & $4(11.1 \%)$ & 0.804 \\
\hline \multicolumn{5}{|l|}{ Previous bronchoscopy } \\
\hline 0 & $24(63.2 \%)$ & $26(68.4 \%)$ & $21(58.3 \%)$ & 0.686 \\
\hline 1 & $11(28.9 \%)$ & $9(23.7 \%)$ & $9(25 \%)$ & \\
\hline$\geq 2$ & $3(7.9 \%)$ & $3(7.9 \%)$ & $6(16.7 \%)$ & \\
\hline \multicolumn{5}{|l|}{ Procedure } \\
\hline EBUS-GS & $21(55.3 \%)$ & $21(55.3 \%)$ & $14(38.9 \%)$ & 0.450 \\
\hline TBB & $7(18.4 \%)$ & $5(13.2 \%)$ & $7(19.4 \%)$ & \\
\hline EBUS-TBNA & $7(18.4 \%)$ & $7(18.4 \%)$ & $8(22.2 \%)$ & \\
\hline EBUS-GS \& & $2(5.3 \%)$ & $1(2.6 \%)$ & $5(13.9 \%)$ & \\
\hline \multicolumn{5}{|l|}{ EBUS-TBNA } \\
\hline TBNA & $0(0 \%)$ & $2(5.3 \%)$ & $0(0 \%)$ & \\
\hline Airway surveillance & $1(2.6 \%)$ & $2(5.3 \%)$ & $2(5.6 \%)$ & \\
\hline STAI-T scores & $34.55 \pm 8.34$ & $36.45 \pm 8.77$ & $34.81 \pm 7.84$ & 0.564 \\
\hline Operative time (min) & $48.42 \pm 22.39$ & $50.26 \pm 21.93$ & $58.19 \pm 26.57$ & 0.176 \\
\hline \multicolumn{5}{|l|}{ Final diagnosis } \\
\hline Non-small cell lung cancer & $8(21.1 \%)$ & $14(36.8 \%)$ & $13(36.1 \%)$ & 0.643 \\
\hline Tuberculosis & $6(15.8 \%)$ & $5(13.2 \%)$ & $4(11.1 \%)$ & \\
\hline Undiagnosed & $20(52.6 \%)$ & $13(34.2 \%)$ & $15(41.7 \%)$ & \\
\hline Other & $4(10.5 \%)$ & $6(15.8 \%)$ & $4(11.1 \%)$ & \\
\hline \multicolumn{5}{|c|}{ Values are presented as mean \pm SD and number (\%). } \\
\hline
\end{tabular}

Throughout the study, a total of bronchoscopic procedures were performed by 13 different physicians assisted by 7 different nurses. No statistically significant differences were observed between the groups regarding the attending staffs and the procedures performed during the bronchoscopy. No major adverse events were reported.

There were no significant differences in STAl-T scores between the groups (Table 1). The baseline STAI-S scores were 39.26 $\pm 8.94,35.62 \pm 8.45$, and $35.64 \pm$ 10.57 for the binaural beat music, the plain music, and the control groups, respectively $(p=0.158)$. The baseline SBP, DBP and HR also yielded non-significant differences between the groups (SBP: $133.95 \pm 22.49,134.03 \pm 19.31$, and 133.03 $\pm 19.07, p=0.973 ;$ DBP: $78.92 \pm 11.88,78.95 \pm 9.01$, and 76.33 $\pm 7.63, p=$ 0.419; HR: $80.29 \pm 13.44,84.34 \pm 14.59$, and $82.94 \pm 16.8, p=0.490$ in the binaural beat music, the plain music, and the control group, respectively) (Table 2 ). 
Table 2

STAI-S scores, SBP, DBP, HR, sedative and analgesic used

\begin{tabular}{|c|c|c|c|c|}
\hline Variable & $\begin{array}{l}\text { Plain music } \\
(n=38)\end{array}$ & $\begin{array}{l}\text { Binaural } \\
(n=38)\end{array}$ & $\begin{array}{l}\text { Control } \\
(n=36)\end{array}$ & P-value \\
\hline \multicolumn{5}{|l|}{ STAI-S scores } \\
\hline Pre & $35.62 \pm 8.45$ & $39.26 \pm 8.94$ & $35.64 \pm 10.57$ & 0.158 \\
\hline Post & $32.03 \pm 8.13$ & $33.09 \pm 7.34$ & $34.79 \pm 8.82$ & 0.360 \\
\hline Mean Change (95\%Cl.) & $-3.92(-6.58,-1.25)$ & $-7.26(-10.22,-4.3)$ & $-1.12(-4.13,1.89)$ & 0.012 \\
\hline \multicolumn{5}{|l|}{ (within group) } \\
\hline \multicolumn{5}{|l|}{ SBP } \\
\hline Pre & $134.03 \pm 19.31$ & $133.95 \pm 22.49$ & $133.03 \pm 19.07$ & 0.973 \\
\hline Post & $138.71 \pm 19.49$ & $124.05 \pm 19.13$ & $130.25 \pm 20.84$ & 0.007 \\
\hline Mean Change (95\%Cl.) & $4.68(-2.41,11.78)$ & $-9.89(-15.76,-4.03)$ & $-2.78(-9.35,3.8)$ & 0.007 \\
\hline \multicolumn{5}{|l|}{ (within group) } \\
\hline \multicolumn{5}{|l|}{ DBP } \\
\hline Pre & $78.95 \pm 9.01$ & $78.92 \pm 11.88$ & $76.33 \pm 7.63$ & 0.419 \\
\hline Post & $78.42 \pm 9.21$ & $73.16 \pm 10.4$ & $78.36 \pm 11.26$ & 0.043 \\
\hline Mean Change (95\%Cl.) & $-0.53(-4.15,3.09)$ & $-5.76(-9.64,-1.89)$ & $2.03(-2.2,6.25)$ & 0.017 \\
\hline \multicolumn{5}{|l|}{ (within group) } \\
\hline \multicolumn{5}{|l|}{ HR } \\
\hline Pre & $84.34 \pm 14.59$ & $80.29 \pm 13.44$ & $82.94 \pm 16.8$ & 0.490 \\
\hline Post & $89.55 \pm 15.77$ & $83.61 \pm 15.34$ & $86.58 \pm 14.12$ & 0.234 \\
\hline Mean Change (95\%Cl.) & $5.21(0.31,10.11)$ & $3.32(0.24,6.39)$ & $3.64(-1.37,8.65)$ & 0.802 \\
\hline \multicolumn{5}{|l|}{ (within group) } \\
\hline Fentanyl (mcg) & $86.49 \pm 38.91$ & $91.45 \pm 43.99$ & $96.53 \pm 49.7$ & 0.628 \\
\hline Midazolam (mg) & $3.43 \pm 1.48$ & $3.61 \pm 1.52$ & $3.75 \pm 1.65$ & 0.681 \\
\hline \multicolumn{5}{|c|}{ Values are presented as mean $\pm \mathrm{SD}$ and mean change $(95 \% \mathrm{Cl}$.). } \\
\hline
\end{tabular}

Post bronchoscopic STAI-S scores were recorded with the mean change of STAI-S scores for $-7.26(95 \% \mathrm{Cl}-10.22$ to $-4.3, \mathrm{p}<0.001)$ in the binaural beat music group, $-3.92(95 \% \mathrm{Cl}-6.58$ to $-1.25, \mathrm{p}=0.005)$ in the plain music group, and $-1.12(95 \% \mathrm{Cl}-4.13$ to $1.89, \mathrm{p}=0.454)$ in the control group. The mean SBP and DBP were significantly decreased from baseline for $-9.89(95 \% \mathrm{Cl}-15.76$ to $-4.03, \mathrm{p}=0.002)$ and $-5.76(95 \% \mathrm{Cl}-9.64$ to $-1.89, \mathrm{p}=0.005)$ in the binaural beat music group, but no significant changes in the plain music and the control groups. The mean HR was increased from baseline for 3.32 (95\% $\mathrm{Cl} 0.24$ to $6.39, \mathrm{p}=$ $0.035)$ in the binaural beat music group, $5.21(95 \% \mathrm{Cl} 0.31$ to $10.11, \mathrm{p}=0.038)$ in the plain music group, and $3.64(95 \% \mathrm{Cl}-1.37$ to $8.65, \mathrm{p}=0.149)$ in the control group (Table 2 and Fig. 2). The mean changes of STAI-S scores, SBP, DBP and HR were compared between the groups (Table 3 ). The binaural beat music group showed a significant reduction of STAI-S scores $(p=0.009)$ and DBP $(p=0.016)$, compared with the control group. Whereas, a reduction of SBP was significantly demonstrated in the binaural beat music group, compared with the plain music group $(p=0.005)$. The amount of sedative and analgesic drug use was non-significantly different between the groups (Table 2). 
Table 3

Comparison of mean change in STAI-S, SBP, DBP and HR between groups

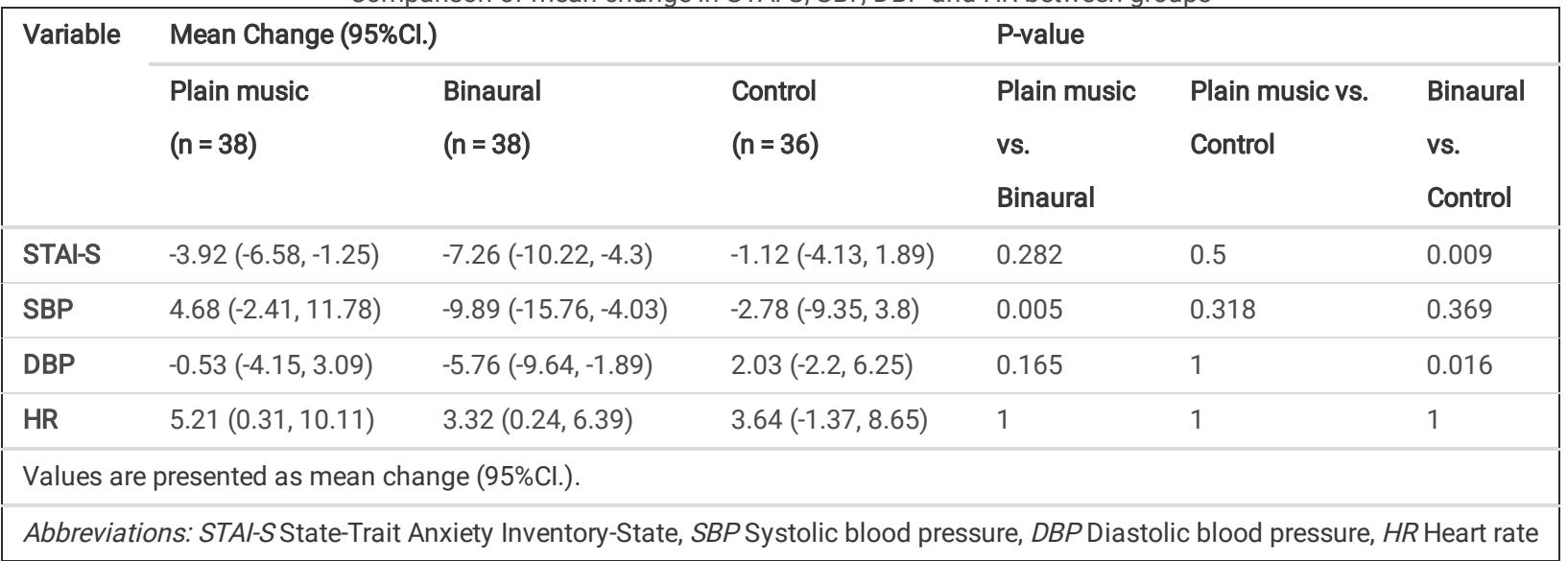

\section{Discussion}

In this study, binaural beat music could effectively reduce the anxiety in subjects undergoing fiberoptic bronchoscopy, with a significant decrease in STAI-S scores, systolic blood pressure, and diastolic blood pressure. To the best of our knowledge, this is a novel study to evaluate the efficacy of binaural beat audio on the perioperative anxiety in bronchoscopy. Prior studies also reported the benefits of binaural beat audio in other procedures. R. Padmanabhan et al showed that binaural beat audio decreases STAI-S scores before general anesthesia in surgery [11]. Whilst, D. Wiwatwongwana et al conducted a study in patients undergoing cataract surgery, which demonstrated the reduction of STAI-S scores, systolic blood pressure, and heart rate in binaural beat music group [12].

Currently, the STAI becomes a standard tool for measurement of preoperative anxiety [13]. In our study, the Spielberger's STAI was applied to measure the level of anxiety level as a subjective test for self-assessment. Furthermore, the objective parameters of anxiety, including SBP, DBP, HR, and sedative drugs, were also used in the procedure. Besides, we compared the effectiveness of binaural beat audio on anxiety reduction with plain music and no musical intervention to explore additional benefits of binaural beat music. The study significantly demonstrated the reduction of SBP, DBP, and STAI-S scores in the binaural beat music group compared to the plain music and the control group. Whereas, no significant effects on HR was identified. Nonetheless, our results suggested that the binaural beat audio may have an additional anxiolytic effects over the plain musical intervention.

The binaural beat audio can create some predictable changes to brainwave activities. With the frequencies of binaural beat, the brain is stimulated by different levels of activation, accordingly to the reticular-thalamic activating system, as a process so called 'entrainment' in previous reports electroencephalogram (EEG) recording [16]. Our study purposed to assess the efficacy of binaural beat audio with $10 \mathrm{~Hz}$ frequency for the reduction of perioperative anxiety. Initially, the $20 \mathrm{~Hz}$ frequency was adjusted to pre-operative anxiety during the first 5 minutes in accordance with the arousal brainwave. Therefore, the $10 \mathrm{~Hz}$ binaural beat could correspondingly enhance the alpha pattern of relaxing state.

There were some limitations in this sudy. We did not objectively test the self-report of hearing impairment in all subjects. So, those with mild hearing loss may not be aware of their impairment and this could affect the results of our study. In addition, subjects in the control group were only blinded until the intervention. This awareness of each individual in the intervention group may cause some bias in the answering of post intervention STAl questionnaires. Physiologic parameters of anxiety, including SBP, DBP, and HR, may reflect the anxiety state of subjects. Another limitation included the lack of EEG recording facilities for the brainwave. Thus, further studies should be recommended to assess the subjects' brainwave by monitoring EEG during the procedure. Other clinical impacts of binaural beat audio on perioperative anxiety, such as oxygen saturation, cough events, and procedure outcomes, need to be also evaluated.

\section{Conclusions}

In conclusion, the binaural beat audio can decrease the level of anxiety during bronchoscopic procedure, measured by STAl questionnaires. Physiologic indicators of anxiety, systolic, and diastolic blood pressure, are also significantly lower in the binaural beat music group. Hence, music therapy with binaural beat music has a potential to relieve anxiety in patients undergoing fiberoptic bronchoscopy.

\section{Abbreviations}

DBP

Diastolic blood pressure

EEG

Electroencephalogram

HR

Heart rate

SBP

Systolic blood pressure 
State-Trait Anxiety Inventory

STAI-S

State-Trait Anxiety Inventory-State

STAI-T

State-Trait Anxiety Inventory-Trait

\section{Declarations}

\section{Ethics approval and consent to participate}

The Institutional Review Board, Royal Thai Army Medical Department, Phramongkutklao College of Medicine approved the study protocol (IRBRTA

1748/2561), and written informed consent was obtained from all study subjects. This study adheres to Consolidated Standards of Reporting Trials guidelines.

\section{Consent for publication}

Not applicable.

\section{Availability of data and materials}

The datasets used and/or analysed during the current study are available from the corresponding author on reasonable request.

\section{Competing interests}

The authors declare that they have no competing interests.

\section{Funding}

None.

\section{Authors' contributions}

The study was designed by PO, PV and NO. PO was responsible for study data collection and statistical analysis. PO, PV and NO contributed to interpretation of study data. PO and NO contributed to drafting and revision of the manuscript. All authors read and approved the final manuscript.

\section{Acknowledgements}

We appreciate all the people involved in this study.

\section{Authors' information}

\section{Email address}

Pornchai Opartpunyasarn

Email: hagao_jungs@hotmail.com

Pornpattana Vichitvejpaisal

Email: g_zard113@hotmail.com

Nittha Oer-areemitr

Email: natt.nittha@gmail.com

\section{Affiliations}

Pulmonary and Critical Care Division, Department of Medicine, Phramongkutklao Hospital, Bangkok, Thailand

Pornchai Opartpunyasarn \& Nittha Oer-areemitr

Department of Medicine, Chulabhorn Hospital, Bangkok, Thailand

Pornchai Opartpunyasarn

Department of Ophthalmology, Chulabhom Hospital, Bangkok, Thailand

Pornpattana Vichitvejpaisal

\section{References}


1. Putinati S, Ballerin L, Corbetta L, Trevisani L, Potena A. Patient satisfaction with conscious sedation for bronchoscopy. Chest. 1999;115:1437-1440. https://journal.chestnet.org/article/S0012-3692(15)35305-8/fulltext

https://pubmed.ncbi.nlm.nih.gov/10334165/

2. Houghton CM, Raghuram A, Sullivan PJ, O’Driscoll R. Premedication for bronchoscopy: a randomised double blind trial comparing alfentanil with midazolam. Respir Med. 2004;98:1102-7.

https://www.resmedjournal.com/article/S0954-6111(04)00151-9/fulltext

https://pubmed.ncbi.nlm.nih.gov/15526811/

3. Matot I, Kramer M. Sedation in outpatient bronchoscopy. Respir Med. 2000;94:1145-53.

https://www.resmedjournal.com/article/S0954-6111(00)90926-0/fulltext

https://pubmed.ncbi.nlm.nih.gov/11192948/

4. Nilsson U. The anxiety and pain-reducing effects of music interventions: a systematic review. AORN J. 2008;87:780-807.

https://aornjournal.onlinelibrary.wiley.com/doi/abs/10.1016/j.aorn.2007.09.013

https://pubmed.ncbi.nlm.nih.gov/18395022/\#: :text=Music\%20intervention\%20had\%20positive\%20effects,to\%20reduce\%20perioperative\%20patient\%20distr

5. Rudin D, Kiss A, Wetz RV, Sottile VM. Music in the endoscopy suite: a meta-analysis of randomized controlled studies. Endoscopy. 2007;39:507-10.

https://www.thieme-connect.com/products/ejournals/abstract/10.1055/s-2007-966362

https://pubmed.ncbi.nlm.nih.gov/17554644/

6. Tam WW, Wong EL, Twinn SF. Effect of music on procedure time and sedation during colonoscopy: a meta-analysis. World J Gastroenterol. 2008;14:533643.

https://www.ncbi.nlm.nih.gov/pmc/articles/PMC2744067/

https://europepmc.org/article/med/18785289

7. Wang MC, Zhang LY, Zhang YL, Zhang YW, Xu XD, Zhang YC. Effect of music in endoscopy procedures: systematic review and meta-analysis of randomized controlled trials. Pain Med. 2014;15:1786-94.

https://academic.oup.com/painmedicine/article/15/10/1786/1959657

https://pubmed.ncbi.nlm.nih.gov/25139786/

8. Tam WW, Lo KK, Hui DS. The effect of music during bronchoscopy: a meta-analysis. Heart Lung. 2016;45:86-94.

https://www.heartandlung.org/article/S0147-9563(15)00363-5/abstract

https://europepmc.org/article/med/26764267

9. Watkins GR. Music therapy: Proposed physiological mechanisms and clinical implications. Clin Nurse Spec. 1997;11:43-50.

https://journals.Iww.com/cns-journal/Abstract/1997/03000/Music_Therapy_Proposed_Physiological_Mechanisms.3.aspx

https://pubmed.ncbi.nlm.nih.gov/9233140/

10. Oster G. Auditory beats in the brain. Sci Am. 1973;229:94-102.

https://www.scientificamerican.com/article/auditory-beats-in-the-brain/

https://pubmed.ncbi.nlm.nih.gov/4727697/

11. Padmanabhan R, Hildreth AJ, Laws D. A prospective, randomized, controlled study examining binaural beat audio and pre-operative anxiety in patients undergoing general anaesthesia for day case surgery. Anaesthesia. 2005;60:874-7.

https://onlinelibrary.wiley.com/doi/full/10.1111/j.1365-2044.2005.04287.x

https://pubmed.ncbi.nlm.nih.gov/16115248/

Page 8/10 
12. Wiwatwongwana D, Vichitvejpaisal P, Thaikruea L, Klaphajone J, Tantong A, Wiwatwongwana A. The effect of music with and without binaural beat audio on operative anxiety in patients undergoing cataract surgery: a randomized controlled trial. Eye (Lond). 2016;30:1407-14.

https://www.nature.com/articles/eye2016160

https://pubmed.ncbi.nlm.nih.gov/27740618/

13. Moerman N, van Dam FS, Muller MJ, Oosting H. The Amsterdam preoperative anxiety and information scale (APAIS). Anesth Analg. 1996;82:445-51.

https://journals.Iww.com/anesthesia-analgesia/Fulltext/1996/03000/The_Amsterdam_Preoperative_Anxiety_and_Information.2.aspx

https://pubmed.ncbi.nlm.nih.gov/8623940/

14. Spielberger C, Gorusch R, Lushene R. State-Trait Anxiety Inventory Manual. Palo Alto: Consulting Psychologists Press, 1970.

15. Spielberger C. State-trait anxiety inventory: a comprehensive bibliography.1989, pp 4-12.

16. Gao X, Cao H, Ming D, Qi H, Wang X, Wang X, et al. Analysis of EEG activity in response to binaural beats with different frequencies. Int J Psychophysiol. 2014;94:399-406.

https://www.sciencedirect.com/science/article/abs/pii/S0167876014016353?via\%3Dihub

https://pubmed.ncbi.nlm.nih.gov/25448376/

\section{Figures}

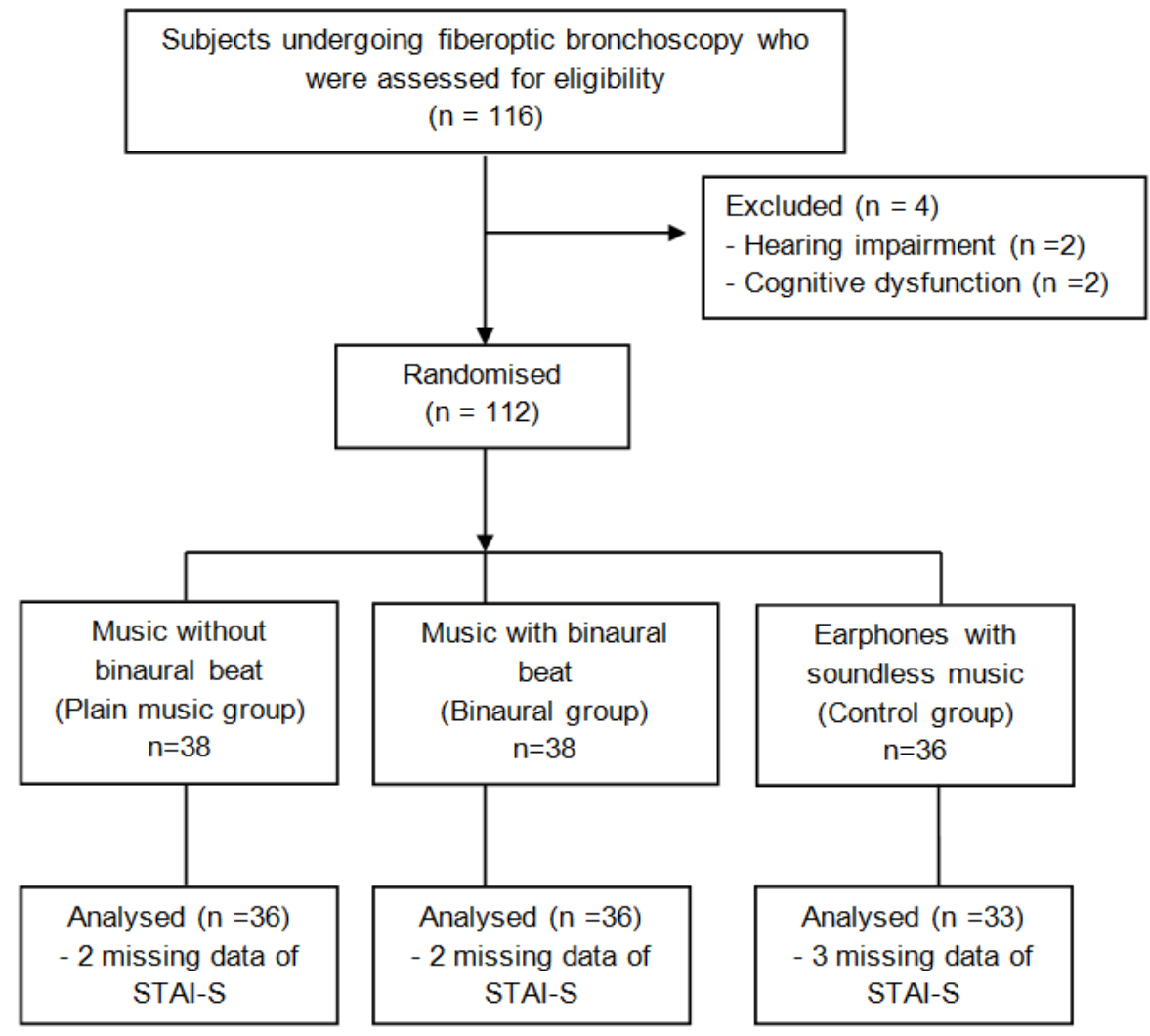

Figure 1

CONSORT flow diagram of study subjects Abbreviations: STAI-S State-Trait Anxiety Inventory-State 


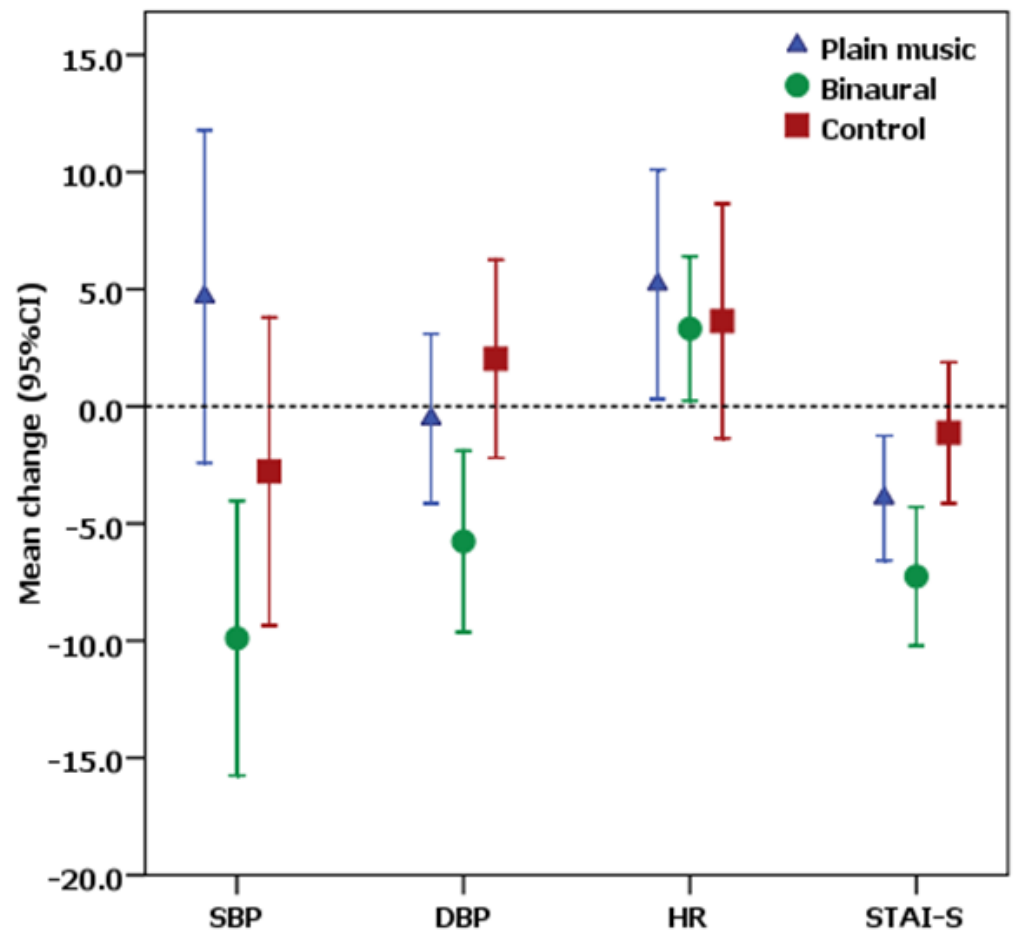

Figure 2

Mean change in SBP, DBP, HR, and STAI-S Abbreviations: SBP Systolic blood pressure, DBP Diastolic blood pressure, HR Heart rate, STAI-S State-Trait Anxiety Inventory-State

\section{Supplementary Files}

This is a list of supplementary files associated with this preprint. Click to download.

- CONSORT2010Checklist.doc 